\title{
(Im)Posturas Jornalísticas: Incompreensões da Revista Veja sobre B. F. Skinner
}

\author{
Marcos Spector Azoubel ${ }^{1}$ \\ Gabriella Mendes Abbud \\ Pontifícia Universidade Católica de São Paulo, São Paulo, SP, Brasil
}

\begin{abstract}
Resumo
A ciência da análise do comportamento e o behaviorismo radical são recorrentemente alvos de incompreensões, pré-conceitos e críticas infundadas, que constituem barreiras para a difusão das propostas filosóficas, conceituais e tecnológicas da área. Os meios de comunicação popular exercem importante papel na difusão de tais visões. Por isso é importante examinar o que é dito sobre a área, a fim de subsidiar ações efetivas para esclarecimento das incompreensões da comunidade de não analistas do comportamento. No Brasil, a revista Veja se destaca como um dos meios de circulação de informações mais populares. O objetivo do presente trabalho foi identificar o que foi publicado na revista Veja sobre behaviorismo radical e análise do comportamento e avaliar criticamente as referências identificadas. A partir de buscas no acervo digital da revista, encontraram-se 67 ocorrências dos termos "Skinner", "análise do comportamento" e "behaviorismo". Foram selecionados para a análise 12 trechos. Dentre estes, 11 contiveram ou incompreensões históricas ou conceituais em relação ao behaviorismo radical e à análise do comportamento.
\end{abstract}

Palavras-chave: Análise do comportamento, behaviorismo radical, incompreensão do behaviorismo, Skinner, mídia popular, revista Veja.

\section{Journalistic (Im)Postures: Misconceptions of Veja Magazine about B. F. Skinner}

\begin{abstract}
The analysis of human behavior and its conceptual variant, radical behaviorism, have been suffering under the constant misunderstanding of its philosophy, preconceptions and unfounded criticism, therefore creating walls to its diffusion, either conceptual, philosophical or technological. Mass media has an important part on this erroneous view and its diffusion. Thus it is primordial to examine what is said about behaviorism, in order to create a plan with actions on how to better explain this analysis of the human behavior to non-behaviorists. In Brazil the popular magazine Veja stands on the spotlight of one of the most important mass media magazines. The aim of this study was to identify what was published in Veja magazine about radical behaviorism and behavior analysis and to critically evaluate its references. A search on the digital magazine collection met 67 occurrences of the terms "Skinner", "behavior analysis" and "behaviorism." There were 12 stretches selected for analysis. Of these, 11 were contained historical or conceptual misunderstandings in relation to the radical behaviorism and behavior analysis.
\end{abstract}

Keywords: Behavior analysis, popular press, Skinner, radical behaviorism, Veja magazine, misunderstandings of behaviorism.

Endereço para correspondência: Pontifícia Universidade Católica de São Paulo, R. Monte Alegre, 984, Perdizes, São Paulo, SP, Brasil 05014-901. E-mail: mazoubel@gmail.com e gabi_abbud@hotmail.com Agradecemos a Daniel Caro pela leitura minuciosa e pelos comentários cuidadosos. 


\section{(Im)Posturas Periodísticas: Malentendidos de la Revista Veja acerca de B. F. Skinner}

\section{Resumen}

La ciencia del análisis conductual y el conductismo radical a menudo son victimas de malentendidos, prejuicios y críticas infundadas, que son barreras para la diseminación de las propuestas filosoficas, conceptuales y tecnológicas. Los medios de comunicación popular desempeñan un rol importante en la difusión de tales puntos de vista. Por esto, es importante examinar lo que se dice sobre el área, para subsidiar medidas eficaces para aclarar los malentendidos de la comunidad de no analistas de la conducta. En Brasil, la revista Veja se destaca como uno de los médios de circulacíon más populares. El objetivo de este trabajo fue identificar lo que publicó la revista Veja acerca del behaviorismo radical y la análisis de la conducta y evaluar críticamente las referencias identificadas. A partir de la búsqueda en el acervo digital de la revista, fueron encontrados 67 extractos con los términos "Skinner", "análisis de la conducta" y "conductismo". Fueron selecionados para análisis 12 extractos. Entre ellos, 11 fueron considerados como conteniendo malentendidos históricos o conceptuales acerca del conductismo radical y la análisis de la conducta.

Palavras clave: Análisis de la conducta, Skinner, conductismo radical, prensa popular, revista Veja, malentendios sobre el conductismo.

O título do presente artigo faz referência ao livro de Sokal e Bricmont (1995/1999), intitulado Imposturas Intelectuais. A obra trata dos abusos cometidos por certos autores das ciências humanas e sociais, que exibem erudição superficial em momentos desnecessários ao se utilizarem de teorias científicas. Os autores denunciam utilizações incorretas dos termos de disciplinas científicas, aplicação de conceitos científicos como analogias a conceitos de outras disciplinas sem qualquer justificativa e a manipulação de frases sem sentido para confundir o leitor. As ciências, incluídas as ciências do comportamento, são alvo de diversos tipos de abusos.

A ciência da análise do comportamento e o behaviorismo radical, filosofia que lhe subsidia, também são recorrentemente vítimas de incompreensões, preconceitos e críticas infundadas (Guimarães, 2003). Os equívocos em relação às suas proposições podem ser encontrados em manuais e livros didáticos da Educação e da Psicologia (Gioia, 2001; Rodrigues, 2005), entre diversos outros materiais. São perpetuadas afirmações incorretas sobre a abordagem, muitas vezes atribuindo características do behaviorismo metodológico de Watson (Guimarães, 2003) ao behaviorismo radical, proposto por B. F. Skinner. O próprio Skinner (1974) dedicou um livro ao esclarecimento de ideias errôneas sobre a filosofia behaviorista radical.

Tais incompreensões são vistas por alguns autores como uma das principais barreiras para a difusão das propostas conceituais e tecnológicas da área (Gioia, 2001; Miraldo, 1985; Morris, 1985; Rodrigues, 2005). Weber (2002) afirma que os estereótipos atribuídos à análise do comportamento produzem rejeição do conhecimento da área e atrapalham no processo de ensino-aprendizagem dessa ciência e da filosofia que lhe subsidia. Deste modo, é importante, para membros da comunidade analítico-comportamental, investigar quais são as ideias equivocadas que se espalham para que se possa planejar melhores estratégias para o devido esclarecimento dos assuntos incompreendidos pela população em geral.

A mídia exerce importante papel na construção da visão da sociedade sobre a análise do comportamento. Por isso, é importante que analistas do comportamento examinem o que é difundido pelos meios de comunicação e, além disso, analisem as contingências que selecionam e mantêm os comportamentos dos comunicadores (Morris, 1985).

Skinner mostrou preocupação recorrente na apresentação das propostas da análise do com- 
portamento para leigos, tanto por meio de livros (e.g., Skinner, 1948, 1971; Skinner \& Vaughan, 1983) quanto por meio de artigos para imprensa popular. Rutherford (2004) realizou uma pesquisa em jornais e revistas populares (e.g. New York Times, Psychology Today) sobre textos de autoria de Skinner a partir da década de 1930 até sua morte, em 1990, e encontrou 50 artigos. Apesar de comunicar-se constantemente com a comunidade em geral, nem sempre o que dizia era entendido corretamente.

No contexto da mídia brasileira, a revista Veja se destaca como um importante meio de circulação de informações. Ela é a revista semanal mais vendida e lida do país e exerce papel relevante na formação de opinião dos leitores brasileiros (Benetti, 2007). Dada a sua importância no cenário nacional, é relevante analisar o que tem sido publicado nessa revista sobre análise do comportamento e behaviorismo radical. Afinal, como dito por Galeano (1971/1982), "a primeira condição para modificar a realidade consiste em conhecê-la" (p. 187).

O objetivo do presente trabalho foi identificar o que foi publicado na revista Veja sobre behaviorismo radical e análise do comportamento desde a sua fundação e avaliar criticamente as referências identificadas, de forma a discutir as informações noticiadas.

\section{Método}

\section{Fonte de Informações}

A decisão sobre a fonte de informação a ser utilizada levou em consideração o fato de que a fonte deve ser a mais direta possível (Luna, 1998). Dito isto, foi utilizado como fonte de informações o "Acervo Digital VEJA" (http:// veja.abril.com.br/acervodigital/home.aspx), disponibilizado gratuitamente pela própria revista. O acervo contém todas as revistas publicadas desde a sua fundação, em 1968.

\section{Procedimento de Busca}

$\mathrm{Na}$ página principal do "Acervo Digital VEJA" foi selecionada a opção "Busca Avançada". Abertos os campos para a busca avança- da, foram aplicados os termos Skinner, Análise do Comportamento e Behaviorismo no campo "Com a expressão exata". Foi realizada uma busca para cada termo da pesquisa. A utilização dos termos resultou, respectivamente, em 42, 17 e 8 ocorrências.

Cada ocorrência descreve a aparição do termo em alguma página da revista. Em caso de repetições de um mesmo termo numa mesma página, é apresentada apenas uma ocorrência relativa a tal página da revista.

\section{Critérios de Exclusão}

Os critérios de exclusão aplicados foram: (a) eliminação de ocorrências repetidas; (b) eliminação de trechos que tratavam de outra pessoa com nome ou sobrenome "Skinner", que não B. F. Skinner; (c) eliminação de trechos em que os termos foram apenas citados e nenhum comentário sobre eles foi proferido; (d) eliminação dos trechos das entrevistas concedidas por Skinner à revista Veja. Ao fim dos procedimentos de exclusão, restaram 12 ocorrências.

\section{Características dos Trechos Excluídos}

Foram realizadas duas entrevistas com Skinner durante a história de publicações da revista, na edição 319 de 25 de novembro de 1974 e na edição 771 de 15 de junho de 1983. Elas foram excluídas por serem consideradas como irrelevantes para a análise, uma vez que representam as opiniões de ideias do autor, de forma que não trariam contribuições para responder ao problema de pesquisa. De qualquer modo, é importante considerar que ele teve duas oportunidades de se comunicar por esta revista com os leitores brasileiros. Por fim, dentre as ocorrências do termo Skinner, a maioria tratava de outras pessoas ou personagens com nome ou sobrenome semelhantes ao de B. F. Skinner ou apenas citava seu nome, sem discutir nada mais (e.g., na introdução à entrevista do mágico James Randi é dito que ele é membro de um comitê para investigação científica de fenômenos alegados como paranormais, juntamente com várias figuras famosas, dentre elas Skinner). Os trechos com tais características foram eliminados. 
Todos os trechos em que havia o termo análise do comportamento estavam no sentido leigo. Não houve qualquer utilização do termo para designar a análise do comportamento como ciência do comportamento baseada no behaviorismo radical. O termo foi usado para tratar dos comportamentos de células, da bolsa de valores, de políticos etc. Exceto por uma referência a uma professora do núcleo de análise do comportamento da Universidade Federal do Paraná, mas foi apresentada uma opinião dela e nada mais foi dito sobre o assunto.

O termo behaviorismo foi usado uma vez para designar o behaviorismo de Watson, em duas outras vezes foi utilizado de forma genérica, sem referir-se a Skinner, a Watson, ou qualquer outro cientista. Em todas as outras ocorrências foram utilizadas para designar o modelo de Skinner. Nos trechos em que estava presente o termo behaviorismo, também estava presente o termo Skinner, de forma que foram eliminadas por se tratarem de repetições.

\section{Procedimento de Análise}

Os parágrafos completos em que apareceram os termos na revista foram transcritos integralmente em uma planilha do Microsoft Excel 2010. Além do campo para transcrição dos trechos, foram adicionadas a página em que cada termo apareceu, a edição e a data de publicação. Após o preenchimento das planilhas com tais informações, os trechos foram lidos pela primeira vez.

A partir da primeira leitura foram definidas duas categorias de equívocos: (a) incompreensão histórica, que se refere a equívocos relacionados a aspectos históricos da análise do comportamento e do behaviorismo radical (e.g., atribuição errônea de determinada técnica ou princípio a um autor, distorção de outros fatos ou acontecimentos relativos à ciência da análise do comportamento ou sua filosofia); (b) incompreensão conceitual, que se refere a equívocos relacionados aos conceitos e princípios da análise do comportamento (e.g., erros na definição de comportamento, uso da palavra "reflexo" para designar um comportamento operante). Os trechos selecionados, as categorias de equívocos atribuídas e as suas justificativas foram apresentados na seção de Resultados e Discussão.

\section{Resultados e Discussão}

Após a realização dos procedimentos descritos no Método, 12 trechos foram selecionados para a análise. Destes, apenas um não teve qualquer erro ou inconsistência teórica categorizada. Nele, diz-se que Skinner possui fama de anti-humanista, afirmação que encontra subsídios na literatura (Rumph et al., 2007), e que era, no momento, o único psicólogo vivo que rivalizava com Rogers como o mais importante. Os demais trechos foram categorizados como contendo incompreensões históricas (Tabela 1), incompreensões conceituais (Tabela 2) ou ambas e foram identificados com um número de 1 a 12, de acordo com a ordem cronológica, para facilitar a leitura.

\section{Incompreensões Históricas}

Um primeiro equívoco, ou ao menos falta de clareza, evidente em todos os trechos em que apareceu a palavra "behaviorismo" é a não diferenciação entre os diversos behaviorismos que existem ou existiram na comunidade científica. Smith (1986) cita a existência de, ao menos, quatro behaviorismos durante a história: o behaviorismo de Watson e os neobehaviorismos de Tolman, Hull e Skinner. Porém, como é possível notar pela Tabela 1, todas as referências parecem ser dirigidas a Skinner, exceto uma que indica Pavlov, junto a Skinner, como um dos precursores do "behaviorismo", dito de forma genérica.

O trecho 2 foi retirado da crítica do filme " $A$ Trama", no qual o autor afirma terem sido utilizadas "teorias comportamentalistas de Skinner" para praticar lavagem cerebral em algumas personagens. Apesar da frase do autor, não há qualquer registro na literatura da análise do comportamento de descrição de técnicas para lavagem cerebral.

No trecho 3 em que era anunciada a morte de Skinner, em 1990, aparece uma sequência de erros históricos. O primeiro foi a atribuição do título de psicanalista ao fundador do beha- 
Tabela 1

Apresentação dos Trechos em que Foram Identificadas Incompreensões Históricas e as Datas de Publicação. Os Números da Segunda Coluna Servem para Identificar o Trecho de Acordo com a Ordem Cronológica

Data de

Publicação Número

Trecho

$20 / 08 / 75$

$29 / 08 / 90$

$29 / 08 / 90$

$30 / 11 / 94$

$01 / 12 / 04$

$16 / 05 / 07$
Cubanos anti-Fidel Castro, originários de Miami? Cubanos fidelistas, de Havana? Espiões russos? Agentes chineses? Terroristas de direita? Os conspiradores de "A trama" jamais são identificados por seu credo político. Sabe-se que pertencem a uma entidade altamente secreta, 2 de nome Parallax, especializada em recrutar homens silenciosos e fortes o bastante para resistirem qualquer tipo de tensão e, se descobertos, de pressão. Psicopatas homicidas, foram cerebralmente lavados por pequenos filmes que misturam as teorias comportamentalistas de Burrhus F. Skinner com retratos falados de Lee Oswald e James Bond (p. 106).

MORRERAM: Burrhus Frederic Skinner, aos 86 anos, psicanalista americano que criou a polêmica escola behaviorista de psicologia, que definia o comportamento humano como resultado de aptidões genéticas que poderiam ser desenvolvidas ou atrofiadas por estímulos ambientais. Ele começou a desenvolver suas teorias em 1948 quando era professor na Universidade de Harvard. Discípulo do russo Ivan Pavlov, formulou uma teoria que propunha modificar o comportamento das pessoas através de recompensas ou punições. Essas idéias foram sistematizadas cinco anos mais tarde quando ele escreveu o livro Ciência e Comportamento Humano, um dos clássicos da psicologia moderna. Para demonstrar sua teoria, ele criou a "caixa de Skinner", um ambiente no qual treinava pacientemente ratos e pombos para realizar tarefas inusitadas, como jogar tênis de mesa. As recompensas vinham na forma de uma alimentação farta e os castigos como choques elétricos. Skinner utilizou o mesmo princípio para propor uma reformulação do ensino com o objetivo de estimular o desempenho dos alunos. Em vez de ter que enfrentar uma prova única, ele propunha que os estudantes deveriam receber uma recompensa para cada tarefa escolar que realizassem. A teoria behaviorista foi reavaliada por seus seguidores quando Skinner cometeu o exagero de isolar a própria filha Deborah para provar que suas idéias tinham fundamento. Dia 18, de leucemia, em Cambridge, Estados Unidos (p. 82).

A parte Uruguaia de Um Milagre também propicia um mergulho no espantoso universo do presídio La Libertad, onde ficavam os presos políticos uruguaios. O presídio era totalmente 4 conduzido pelos ditames da psicologia behaviorista - o comportamentalismo desenvolvido por Burrhus Frederic Skinner. Os carcereiros quebravam a resistência dos prisioneiros através de uma série de humilhações e proibições que também atingiam seus familiares (p. 88).

No final dos anos 50, Chomsky introduziu uma nova e explosiva concepção: derrubou a noção, então em voga entre os chamados behavioristas, como B.F. Skinner, de que a linguagem podia ser ensinada. Sustentou que ela é inata, uma característica genética da espécie. O cérebro humano, disse ele, dispõe de um conjunto de "universais linguísticos", complexo de regras e procedimentos que dá ao homem a possibilidade de construir um ilimitado conjunto de sentenças a partir das palavras conhecidas (p. 75).

"Não dá para descartar tudo o que Freud falou. As teorias de Skinner e Beck, que nada têm de freudianas, confirmam com instrumentos práticos várias coisas que o pai na psicanálise intuiu em seus escritos", avalia Vera Lemgruber, presidente da Associação Psiquiátrica do Rio de Janeiro (pp. 122-124).

Se almejarmos somente a média, seremos medíocres. Se almejarmos a excelência, seremos excelentes. Meu curso de administração dava muita ênfase à psicologia. Foi assim que conheci pessoalmente B.F. Skinner, Carl Rogers e Erik Erikson. O que me chamou a atenção foi a escassa literatura no que chamarei de comportamento exemplar. Ausência de doença não significa ter um corpo saudável e atlético. Ausência de neuroses e fobias não significa ser uma pessoa excepcional. Por que tão poucos modelos de excelência humana são apresentados aos pacientes como exemplos a ser (sic) seguidos? (p. 24). 
$16 / 05 / 07$
A primeira experiência de uso da tecnologia de ensino deu-se com as máquinas concebidas pelo psicólogo americano Burrhus Frederic Skinner, programadas para fazer perguntas que ganhavam complexidade a cada resposta correta. Acreditava-se que o reflexo condicionado 9 pela tal máquina estimularia o aprendizado. Com a explosão dos computadores na década de 70, o assunto ressurgiu na contramão do que pregava Skinner: a nova corrente de entusiastas da tecnologia, encabeçada pelo doutor em Matemática Seymour Papert, defendia a tese de que caberia às crianças programar as máquinas- e não o contrário (pp. 88-89).

Essa dupla impostura, porém, terá de resistir às más intenções do sous-chef que herdou o restaurante, o sinistro Skinner (assim batizado em referência ao cientista Burrhus Frederic 10 Skinner, que utilizava experimentos com ratos para demonstrar suas teorias behavioristas), e à perfídia do crítico gastronômico Anton Ego, que perdeu o prazer à mesa e só o encontra arrasando os estabelecimentos que frequenta (p. 131). viorismo radical e crítico claro da psicanálise, cujas divergências estão presentes em diversas de suas obras (cf. Skinner, 1953, 1954, 1957, 1974, entre outras). Além deste, outro equívoco aparece na informação obscura de que sua teoria teria sido reavaliada depois de cometer excessos isolando uma de suas filhas, Deborah. Fato negado pela própria filha, apesar do mito espalhado por algum tempo. Neste mesmo trecho, afirmam que ele teria começado a desenvolver sua teoria em 1948. Nesta data, porém, já havia publicado algumas obras marcantes no começo da formulação da sua teoria (cf. Skinner, 1938, 1945).

No trecho 4, uma das matérias da Veja informa que uma cadeia uruguaia se baseava em princípios do "behaviorismo" para "quebrar a resistência dos prisioneiros através (sic) de uma série de humilhações". O autor deste trecho demonstrou total desconhecimento sobre a posição Skinneriana a respeito de práticas coercitivas. Skinner propõe, inclusive, uma sociedade não punitiva (Skinner, 1990) para minimizar grande parte dos nossos problemas sociais.

No trecho 5 é feita a afirmação de que Chomsky simplesmente derrubou a teoria de Skinner sobre o ensino da linguagem. Tal afirmação foi feita sem qualquer tipo de parcimônia, como se esse fosse um fato banal e bem estabelecido. Havia, certamente, por parte do autor, o desconhecimento sobre respostas dadas por analistas do comportamento (e.g., MacCorquodale, 1970) às críticas de Chomsky e as pesquisas realizadas na área de comportamento verbal (e.g., Catania, Matthews, \& Shimoff, 1982; Davison
\& Kirkwood, 1968; Shillingsburg, Powell, \& Bowen, 2013).

No próximo trecho (7) há uma citação de Vera Lemgruber, citação essa que é extremamente obscura: o que Skinner confirmou sobre o que Freud intuiu? É certo que Skinner, em diversas de suas obras, cita o trabalho de Freud, reconhecendo sua importância e pioneirismo (cf. Skinner, 1953/2003). Contudo, a maior parte das vezes em que Freud é citado, Skinner está fazendo uma crítica negativa. A frase é feita sem qualquer justificativa ou esclarecimento sobre quais foram as confirmações e sobre quais foram as intuições de Freud.

Outro equívoco histórico aparece no trecho 8, quando um colunista da revista, que afirma ter estudado psicologia em sua graduação de administração, critica Skinner, além de outros psicólogos reconhecidos, por não apresentarem uma visão de excelência para o homem, mas lidarem com formas de evitar doenças. Tal afirmação é completamente desconexa com a história de Skinner como autor, já que diversas de suas publicações (e.g., Skinner, 1948, 1990) tinham como objetivo a proposição de um mundo melhor, a partir da "construção de pessoas melhores" por meio de ambientes que selecionem e mantenham comportamentos socialmente relevantes. Era evidente a sua preocupação com a formação de pessoas "excelentes" pela sua recorrente atenção à educação como ferramenta de mudança, como ilustra a seguinte citação: "A educação é o estabelecimento de comportamentos que serão vantajosos para o indivíduo e para outros em algum tempo futuro" (Skinner, 1953/2003, p. 437). 
Quando a revista Veja citou a proposta das máquinas de ensinar de Skinner, no trecho 9, informou aos leitores que aquela teria sido a primeira proposta de utilização de tecnologia para a educação. Tal afirmação é descabida mesmo sem qualquer conhecimento sobre a história da análise do comportamento, pois o significado de "tecnologia" é bastante amplo e a afirmação é feita sem citar qualquer fonte ou explicitar as justificativas para tal afirmação. De qualquer forma, este é mais um erro histórico, visto que o próprio Skinner (1984) admitiu ter se baseado nas máquinas de ensinar propostas anos antes por Sidney Pressey.

O último equívoco histórico categorizado é apresentado no trecho 10 , e diz respeito à afirmação, encontrada na crítica do filme " $R a$ tatouille", de que Skinner era um cientista que utilizava ratos para demonstrar sua teoria. Há aí, pelo menos, dois erros. O primeiro é que Skinner não utilizou ratos para demonstrar sua teoria, mas elaborou sua teoria a partir de dados produzidos com animais (cf. Skinner, 1950, 1956). A ordem não foi elaborar uma teoria para então demonstrá-la com experimentos envolvendo ratos. $\mathrm{O}$ segundo aspecto deste trecho que, se não está errado, pode no mínimo induzir ao erro, é que trabalhou com outras espécies de sujeitos de pesquisa (e.g., Morse \& Skinner, 1957) e a sua principal preocupação era com o comportamento humano. Seu interesse no comportamento humano, mesmo ao estudar o comportamento de outras espécies, fica evidente no trecho a seguir:

O leitor deve ter percebido que quase nenhuma extensão ao comportamento humano é feita ou sugerida. Isto não significa que se espere que ele esteja interessado no comportamento do rato por si mesmo. A importância de uma ciência do comportamento se deriva em grande parte da possibilidade de uma eventual extensão às questões humanas. (Skinner, 1938, p. 441)

\section{Incompreensões Conceituais}

Foram recorrentes os erros conceituais quanto à definição de comportamento, de reforçamento positivo e de reforçamento negativo. No trecho mais antigo em que se encontrou erro conceitual (ver Tabela 2), há a afirmação de que Skinner "descobriu a importância que possuía a atitude de apoio dentro da aprendizagem e do condicionamento". Tal frase parece não encontrar suporte na obra de Skinner.

O trecho 3, que anuncia a morte de Skinner, anuncia também o desconhecimento do autor da matéria da revista quanto aos conceitos comportamentais. Ele atribui a Skinner a definição de comportamento como "resultado de aptidões genéticas que poderiam ser desenvolvidas ou atrofiadas por estímulos ambientais". O autor deste trecho confunde a definição de comportamento com seus determinantes. Skinner (1953) definiu comportamento como uma relação entre o organismo e seu ambiente e a história destas relações determinaria o comportamento. O mesmo trecho traz ainda outra incompreensão ao afirmar que Skinner propunha modificar o comportamento por meio de recompensa e punições. Ele propunha como objetivos da análise do comportamento a predição, o controle e a interpretação do comportamento (Skinner, 1974), não apenas a modificação de comportamentos. Além disso, dedicou-se a denunciar e descrever as relações de controle do comportamento em diversos textos (e.g., Skinner, 1971, 1974).

Diz-se, posteriormente, no trecho 6, que o objetivo da teoria Skinneriana é "se deter na realidade observável dos transtornos e seus tratamentos". Tal postulação, entretanto, não encontra qualquer subsídio no behaviorismo radical. Além disso, Skinner rompeu com o behaviorismo metodológico (Skinner, 1974) e com os operacionistas (Skinner, 1945) em grande medida por divergir deles ao considerar importante trabalhar com eventos privados, não observáveis publicamente e não sujeitos à verdade por consenso.

No trecho 9, um erro conceitual grave é cometido ao tratar sobre a proposta das máquinas de ensinar. A reportagem traz a afirmação de que o reflexo condicionado pela máquina estimularia o aprendizado. Porém, o conceito de reflexo não é tratado durante a proposição de aprendizagem por meio de máquinas de ensinar. Para Skinner (1968), as mudanças esperadas são nos comportamentos operantes e, por isso, dizem respeito 
Tabela 2

Apresentação dos Trechos em que Foram Identificadas Incompreensões Conceituais e as Datas de Publicação. Os Números da Segunda Coluna Servem para Identificar o Trecho de Acordo com a Ordem Cronológica
Data de
Número Trecho

$25 / 03 / 73-2-1$

A teoria do reforço positivo é de autoria de Burrusf (sic) Skinner, que descobriu a importância que possuía a atitude de apoio dentro da aprendizagem e do condicionamento (p. 58).

MORRERAM: Burrhus Frederic Skinner, aos 86 anos, psicanalista americano que criou a polêmica escola behaviorista de psicologia, que definia o comportamento humano como resultado de aptidões genéticas que poderiam ser desenvolvidas ou atrofiadas por estímulos ambientais. Ele começou a desenvolver suas teorias em 1948 quando era professor na Universidade de Harvard. Discípulo do russo Ivan Pavlov, formulou uma teoria que propunha modificar o comportamento das pessoas através de recompensas ou punições. Essas idéias foram sistematizadas cinco anos mais tarde quando ele escreveu o livro Ciência e Comportamento Humano, um dos clássicos da psicologia moderna. Para demonstrar sua teoria, ele criou a "caixa de Skinner", um ambiente no qual treinava pacientemente ratos e pombos para realizar tarefas inusitadas, como jogar tênis de mesa. As recompensas vinham na forma de uma alimentação farta e os castigos como choques elétricos. Skinner utilizou o mesmo princípio para propor uma reformulação do ensino com o objetivo de estimular o desempenho dos alunos. Em vez de ter que enfrentar uma prova única, ele propunha que os estudantes deveriam receber uma recompensa para cada tarefa escolar que realizassem. A teoria behaviorista foi reavaliada por seus seguidores quando Skinner cometeu o exagero de isolar a própria filha Deborah para provar que suas idéias tinham fundamento. Dia 18, de leucemia, em Cambridge, Estados Unidos (p. 82).

Nem todas as correntes da psicologia se dispuseram a falar a língua do DSM. "Era necessário adotar o conceito médico de diagnóstico e o foco na comprovação experimental dos tratamentos, o que para alguns significava uma submissão da psicologia à medicina", diz o psiquiatra José Alberto Del Porto, professor da Escola Paulista de Medicina. As que se adaptaram melhor foram as correntes comportamental e cognitiva, ambas surgidas nos Estados Unidos nos anos 50 e 60,

01/12/04 6 e que defendiam um olhar mais pragmático sobre o fenômeno psicológico. Burrhus Frederic Skinner, principal nome da escola comportamental, achava que mais importante do que abrir a caixa-preta da mente, como queria Freud, era se deter sobre a realidade observável dos transtornos e seus tratamentos. É difícil resumir sua complexa teoria, exposta em livros como Ciência e Comportamento Humano, que tem mais de 500 páginas. Ela se baseia nos conceitos de estímulo, resposta e reforço, e o tratamento hoje utilizado para fobias, no qual o paciente é incentivado a enfrentar aquilo que teme, é baseado em suas técnicas (pp. 121-122).

A primeira experiência de uso da tecnologia de ensino deu-se com as máquinas concebidas pelo psicólogo americano Burrhus Frederic Skinner, programadas para fazer perguntas que ganhavam complexidade a cada resposta correta. Acreditava-se que o reflexo condicionado pela tal máquina

16/05/07 9 estimularia o aprendizado. Com a explosão dos computadores na década de 70, o assunto ressurgiu na contramão do que pregava Skinner: a nova corrente de entusiastas da tecnologia, encabeçada pelo doutor em Matemática Seymour Papert, defendia a tese de que caberia às crianças programar as máquinas- e não o contrário (pp. 88-89).

As bases da terapia cognitivo-comportamental, cujas taxas de sucesso são bastante altas, remontam às teorias do médico russo Ivan Pavlov (1849-1936) e às do psicólogo americano Burrhus Frederic Skinner (1904-1990), precursores do behaviorismo. Pavlov formulou a tese do reflexo condicionado, segundo a qual a repetição constante de um estímulo "ensina" o sistema nervoso a responder invariavelmente da mesma forma. Sua teoria foi elaborada a partir de estudos com cães que eram alimentados depois que ele tocava um sino. Com o tempo, Pavlov constatou 11 que bastava tocar o sino para que os animais salivassem. Skinner, por sua vez, chegou ao conceito de condicionamento operante, por meio de experiências com ratos de laboratório. Quando os roedores apertavam um botão, uma portinhola com comida se abria. Os ratos, por fim, aprenderam que, para comer, era preciso pressionar o botão. A diferença entre o reflexo condicionado de Pavlov e o condicionamento operante de Skinner é que o primeiro é uma resposta a um estímulo puramente externo (o sino toca, o cachorro saliva), ao passo que o segundo é o hábito produzido por uma ação estranha à natureza do animal (o rato aperta botão para comer) (p. 154). 
aos processos envolvidos no condicionamento operante.

O último trecho (11) apresenta um erro na definição de comportamento operante que, segundo uma das reportagens, seria "o hábito produzido por uma ação estranha à natureza do animal (o rato aperta botão para comer)". Aparentemente, o que está sendo chamado de "hábito" deve ser a recorrência de respostas de uma mesma classe de respostas (i.e., conjuntos de respostas que produzem consequências reforçadoras semelhantes; Skinner, 1953). Um segundo erro contido em tal definição diz respeito ao fato de possuir características teleológicas, atribuindo intencionalidade às ações do rato. As explicações com essas características foram criticadas por Skinner (1953), que defendia que a história de reforçamento determinaria o comportamento e não seus objetivos futuros.

Em resumo, a quase totalidade das frases proferidas na revista Veja sobre análise do comportamento, behaviorismo radical e Skinner é incorreta ou feita de forma potencialmente indutora de erros. Isto deve ser um alerta quanto à qualidade da revista, mas principalmente quanto ao nosso poder de reação. A primeira publicação com incorreções encontrada nesta pesquisa data de 1973 e, desde então, pouca coisa mudou quando a revista trata da análise do comportamento.

Uma reflexão importante suscitada pelas incompreensões encontradas é a de que boa parte delas consistem em críticas nefastas, que atribuem erroneamente a Skinner uma abordagem com técnicas aversivas. Críticas com conteúdo similar foram amplamente difundidas nas décadas de 1960 e 1970, mesma década do lançamento do filme Laranja Mecânica (1971), do diretor Stanley Kubrick. De fato, este período foi marcado pelo uso de alguns procedimentos e técnicas bastante questionáveis, como o uso indiscriminado de punição nas então chamadas terapias aversivas (Kazdin, 1978). Todavia, tais práticas nunca foram defendidas como consenso na área (cf. Sidman, 1989) e nem representam a posição Skinneriana (cf. Skinner, 1990).

Ademais, ainda que muitos procedimentos aversivos tenham sido lamentavelmente realizados em nome da análise do comportamento, não faz nenhum sentido atribuir a Skinner tais feitos, uma vez que descrever os efeitos deletérios do controle aversivo e as alternativas para seu uso foi um de seus maiores esforços ao longo de sua obra, se não o maior. A insensatez de tal atribuição fica evidente quando, em uma entrevista para a própria revista Veja em junho de 1983, Skinner foi questionado sobre a má fama do behaviorismo. Ele, então, respondeu:

Lamento, como todo mundo, que certas drogas pesquisadas com fins farmacêuticos sejam usadas por viciados, mas nem por isso vai defender-se o fim da pesquisa farmacêutica. Não se acaba com os automóveis porque motoristas bêbados os usam para matar. Tudo pode ser usado para fins sinistros e isto vale para a tecnologia do comportamento. O fato é que pessoas habilidosas sempre souberam manipular o comportamento de outras. Só que o faziam intuitivamente, como uma arte. Alguns tinham o talento, outros não. Com o behaviorismo, explicamos como isto se faz. (Cruz, 1983, p. 6)

Em sua visão (Skinner, 1953, 1971), a análise do comportamento, se bem utilizada, poderia auxiliar na resolução de grandes problemas sociais. Porém, a descrição de regularidades no comportamento humano e a derivação de leis comportamentais podem servir para previsão, controle e interpretação de quaisquer comportamentos, tanto os eticamente considerados maus quanto os bons.

É importante salientar que nem toda crítica à análise do comportamento deve ser atribuída às incompreensões de suas propostas. Como exemplos, Skinner (1953) discutiu sobre o fato de o behaviorismo radical desagradar a diversas pessoas por ir de encontro à longa tradição que encara o homem como um ser livre, cujas ações são motivadas por espontâneas mudanças interiores e não pela sua história. Winett e Winkler (1972), em revisão de pesquisas comportamentais aplicadas em salas de aula, apontaram que os analistas do comportamento vinham ajudando a manter o status quo das instituições escolares. Holland (1978), a partir de um exame da atuação dos analistas do comportamento em contextos aplicados, denuncia a existência de grande número de profissionais que trabalham modifican- 
do comportamentos dos sujeitos vítimas das contingências dispostas, ao invés de atuar alterando as contingências que selecionam e mantêm os comportamentos daqueles sujeitos. Assim como nesses casos, é absolutamente possível que alguém se oponha a certos aspectos éticos, conceituais, filosóficos ou técnicos da abordagem comportamental sem incorrer em erros. Porém, a partir das análises feitas na presente pesquisa, não foram encontrados posicionamentos críticos baseados em informações condizentes com as propostas da análise do comportamento. É provável que as críticas bem fundamentadas representem uma minoria.

Por fim, vale observar que os procedimentos de pesquisa aqui utilizados poderiam servir para análise dos conteúdos de outras revistas, de jornais, blogs e outros meios de comunicação. Quanto mais informações sobre os tipos de incompreensões existentes, mais subsídios para trabalhar na contramão e, finalmente, informar a população sobre os benefícios que uma análise do comportamento pode trazer.

Morris (1985) sugeriu que os analistas do comportamento se dedicassem à educação de comunicadores com cursos, palestras e aulas. Talvez este seja um caminho interessante a seguir, ainda mais se considerarmos que a internet pode facilitar bastante o trabalho de divulgação e diálogo com os comunicadores. Além disso, as mídias tradicionais perderam bastante do seu poder e as mídias sociais ganharam espaço. Este é um campo aberto e mais democrático para a divulgação dos conceitos e propostas da análise do comportamento.

Neste sentido, a utilização dos conhecimentos produzidos pela área sobre comportamento humano poderia servir para análise das contingências selecionadoras e mantenedoras dos comportamentos envolvidos na comunicação de incompreensões sobre behaviorismo radical e análise do comportamento. A partir de tais análises, poderiam ser propostas mudanças nessas contingências. Além disso, nossas técnicas e procedimentos de ensino poderiam ser usados no ensino de análise do comportamento para jornalistas e o público em geral.

Uma parte da responsabilidade da atuação no sentido de divulgar o que a análise do com- portamento tem a oferecer cabe às associações da área e às universidades. Quanto mais os analistas do comportamento atravessarem os muros de suas instituições e conversarem com quem está fora, maiores as chances de que a comunidade possa receber informação de quem entende de análise do comportamento: os próprios analistas do comportamento.

A utilização de redes sociais e de blogs voltados para o público leigo e para estudantes de psicologia é uma forma de atuação possivelmente efetiva para esclarecimento de incompreensões sobre behaviorismo radical e análise do comportamento. Na mesma direção, cabe esforço contínuo das associações de analistas do comportamento em pesquisar o que tem sido divulgado sobre análise do comportamento e esclarecer publicamente as incompreensões divulgadas. Por parte das universidades ou outras instituições de ensino, um caminho pode ser o oferecimento de cursos de extensão e aprimoramento abertos a profissionais não analistas do comportamento com objetivo de ensinar princípios básicos sobre comportamento humano e pressupostos filosóficos do behaviorismo radical.

Esforços podem ser realizados por analistas do comportamento para publicação de materiais didáticos que descrevam corretamente os conceitos da área, a fim de contornar os problemas apontados por Gioia (2001) sobre os equívocos presentes em livros para formação de professores. Também pode ser relevante o empenho em apresentar trabalhos científicos em congressos voltados não apenas à análise do comportamento e publicar artigos em periódicos de psicologia geral ou de outras disciplinas. Além da publicação em periódicos científicos, a produção de textos para revistas de divulgação científica e exposição das propostas da análise do comportamento em outros meios de comunicação, como programas televisivos, jornais e revistas, podem contribuir para divulgação da análise do comportamento de forma consistente com o conhecimento produzido pela área.

Cabe considerar que a linguagem técnica da análise do comportamento é apontada (Axelrod, 1992; Fantuzzo \& Atkins, 1992; Miraldo, 1985) como uma possível barreira para a aceitação e o entendimento dos conhecimentos analítico-com- 
portamentais. Logo, pode ser valoroso adaptar o linguajar ao dialogar com audiências leigas em análise do comportamento.

Por fim, conhecimento científico pode ser entendido como descrição de leis que tornem mais efetivas as ações em relação aos eventos descritos (Skinner, 1953). Este conhecimento, então, envolve tanto os produtos do comportamento do cientista que descreve relações existentes no mundo quanto o comportamento efetivo daquele que age sob controle das leis científicas. Desta forma, é importante que o analista do comportamento se engaje não apenas na produção de descrições de relações comportamentais, mas também na difusão correta de tais descrições, de forma a tornar mais prováveis comportamentos sob controle do conhecimento produzido pela análise do comportamento.

\section{Referências}

Axelrod, S. (1992). Disseminating an effective educational technology. Journal of Applied Behavior Analysis, 25(1), 31-35. doi:10.1901/ jaba.1992.25-31

Benetti, M. (2007). A ironia como estratégia discursiva da revista Veja. Encontro da Associação Nacional dos Programas de Pós-graduação em Comunicação, 35-45.

Catania, A. C., Matthews, B. A., \& Shimoff, E. (1982). Instructed versus shaped human verbal behavior: Interactions with nonverbal responding. Journal of the Experimental Analysis of Behavior, 38(3), 233-248. doi:10.1901/jeab.1982.38-233

Cruz, S. S. (1983, jun.). Entrevista: B. F. Skinner. Veja, 771, 3-6.

Davison, M. C., \& Kirkwood, B. J. (1968). Response cost and the control of verbal behavior under free-operant avoidance schedules. Journal of the Experimental Analysis of Behavior, 11(2), 173176.

Fantuzzo, J., \& Atkins, M. (1992). Applied behavior analysis for educators: Teacher centered and classroom based. Journal of Applied Behavior Analysis, 25(1), 37-42. doi:10.1901/ jaba.1992.25-37

Galeano, E. (1982). As veias abertas da América Latina. Rio de Janeiro, RJ: Paz e Terra. (Original publicado em 1971)
Gioia, P., S. (2001). A abordagem behaviorista radical transmitida pelo livro de psicologia direcionado à formação de professores (Tese de doutorado, Pontifícia Universidade Católica de São Paulo, SP, Brasil).

Guimarães, R. P. (2003). Deixando o preconceito de lado e entendendo o behaviorismo radical. Psicologia: Ciência e Profissão, 23(3), 60-67.

Holland, J. G. (1978). Behaviorism: Part of the problem or part of the solution? Journal of Applied Behavior Analysis, 11(1), 163-174.

Kazdin, A. E. (1978). History of behavior modification: Experimental foundations of contemporary research. Baltimore, MD: University Park Press.

Luna, S. V. (1998). Planejamento de pesquisa: Elementos para uma análise metodológica. São Paulo, SP: EDUC.

MacCorquodale, K. (1970). On Chomsky's review of Skinner's Verbal Behavior. Journal of the Experimental Analysis of Behavior, 13(1), 83-99.

Miraldo, C. M. V. (1985). Conhecimento e crenças de estudantes de Psicologia acerca da Análise Experimental do Comportamento (Dissertação de mestrado, Universidade de São Paulo, SP, Brasil).

Morris, E. K. (1985). Public information, dissemination, and behavior analysis. The Behavior Analyst, 8(1), 95-110.

Morse, W., \& Skinner, B. (1957). A second type of superstition in the pigeon. The American Journal of Psychology, 70(2), 308-311.

Rodrigues, M. E. (2005). A contribuição do Behaviorismo Radical para a formação de professores - Uma análise a partir das dissertações e teses no período de 1970 a 2002 (Tese de doutorado, Pontifícia Universidade Católica de São Paulo, SP, Brasil).

Rumph, R., Ninness, C., McCuller, G., Holland, J., Ward, T., \& Willbourn, T. (2007). "The Shame of American Education" Redux. Behavior and Social Issues, 16(1), 27-41. doi:10.5210/bsi. v16i1.399

Rutherford, A. (2004). A "visible scientist": BF Skinner's writings for the popular press. European Journal of Behavior Analysis, 5(2), 109120. doi:10.1080/15021149.2004.11434237

Shillingsburg, M. A., Powell, N. M., \& Bowen, C. N. (2013). Teaching children with autism spectrum disorders to mand for the removal of stimuli that 
prevent access to preferred items. The Analysis of Verbal Behavior, 29(1), 51-57. doi:10.1901/ jaba.1985.18-111

Sidman, M. (1989). Coercion and its fallout. Boston, MA: Authors Cooperative.

Skinner, B. F. (1938). The behavior of organisms: An experimental analysis. Oxford, England: Appleton-Century.

Skinner, B. F. (1945). The operational analysis of psychological terms. Psychological Review, 52(5), 270-277.

Skinner, B. F. (1948). Walden II. New York: Macmillan.

Skinner, B. F. (1950). Are theories of learning necessary? Psychological Review, 57(4), 193-216.

Skinner, B. F. (1953). Science and human behavior. New York: Macmillan.

Skinner, B. F. (1954). Critique of psychoanalytic concepts and theories. The Scientific Monthly, 79, 300-305.

Skinner, B. F. (1956). A case history in scientific method. American Psychologist, 11(5), 221-233.

Skinner, B. F. (1957). Verbal behavior. New York: Appleton-Century-Crofts.

Skinner, B. F. (1968). The technology of teaching. New York: Appleton-Century-Crofts.

Skinner, B. F. (1971). Beyond freedom and dignity. New York: Alfred A. Knopf.

Skinner, B. F. (1974). About behaviorism. New York: Alfred A. Knopf.
Skinner, B. F. (1984). The shame of American education. American Psychologist, 39(9), 947-954.

Skinner, B. F. (1990). The non-punitive society. $J a-$ panese Journal of Behavior Analysis, 5, 98-106.

Skinner, B. F. (2003). Ciência e comportamento Humano. São Paulo, SP: Martins Fontes. (Original publicado em 1953)

Skinner, B. F., \& Vaughan, M. E. (1983). Enjoy old age: A program of self-management. New York: W. W. Norton.

Smith, L. D. (1986). Behaviorism and logical positivism: A reassessment of the alliance. Stanford, CA: Stanford University Press.

Sokal, A., \& Bricmont, J. (1999). Imposturas intelectuais. Rio de Janeiro, RJ: Record. (Original publicado em 1995)

Weber, L. N. D. (2002). Conceitos e pré-conceitos sobre o behaviorismo. Psicologia Argumento, 20(31), 29-38.

Winett, R. A., \& Winkler, R. C. (1972). Current behavior modification in the classroom: Be still, be quiet, be docile. Journal of Applied Behavior Analysis, 5(4), 499-504.
Recebido: $20 / 10 / 2015$

$1^{a}$ revisão: 08/01/2016

$2^{a}$ revisão: $28 / 02 / 2016$

Aceite final: 28/02/2016 